\title{
Implementasi Peraturan Bupati Pelalawan Nomor 45 Tahun 2012 Tentang Perubahan Pedoman Penilaian PNS Berprestasi
}

\author{
Wan Marlina Rusnita*, Meyzi Heriyanto, dan Tuti Khairani Harahap \\ Program Magister Ilmu Administrasi, Fakultas Ilmu Sosial dan Ilmu Politik, \\ Universitas Riau
}

\begin{abstract}
Abstrak Tujuan penelitian ini untuk mengetahui dan menganalisis Implementasi Peraturan Bupati Nomor 45 Tahun 2012 Tentang Perubahan Pedoman Penilaian PNS Berprestasi di Lingkungan Pemerintah Kabupaten Pelalawan, serta faktor-faktor yang mempengaruhinya. Metode yang digunakan adalah pendekatan deskriptif kualitatif. Teknik pengumpulan data diperoleh dari wawancara, observasi dan dokumen. Analisis data menggunakan konsep trianggulasi. Hasil penelitian menunjukkan bahwa implementasi Peraturan Bupati Nomor 45 Tahun 2012 Tentang Perubahan Pedoman Penilaian Pegawai Negeri Sipil Berprestasi di Lingkungan Pemerintah Kabupaten Pelalawan belum terlaksana secara maksimal. Faktor-faktor yang mempengaruhi implementasi kebijakan yaitu konsistensi, motivasi dan koordinasi.
\end{abstract}

Kata kunci: Kebijakan, Penilaian, Pegawai Negeri Sipil, Kualitatif, Kabupaten Pelalawan

\begin{abstract}
The purpose of this study is to find out the description and analysis about the Implementation of Regent Regulation Number 45 of 2012 about the revision of Procedure of Outstanding Civil Servant Appraisal in the Pelalawan District Government. The method of this study is descriptive qualitative approach. The prime date was collected by interviewing and doing observation and the secondary one was collected from the document. The data was analyzed by using triangulation concept. The result of this study showed that the Implementation of Regent Regulation Policy Number 45 of 2012 about the revision of procedure of outstanding Civil Servant Appraisal in the Pelalawan District Government is not maximally implemented. There are some factors founded from this study that influence the policy implementation which are consistency, motivation, and coordination.
\end{abstract}

Keywords: Policy, Assessment, Civil Servant, Qualitative, Pelalawan District 


\section{PENDAHULUAN}

Kinerja Pegawai Negeri Sipil Kabupaten Pelalawan dalam memberikan pelayanan kepada masyarakat masih banyak kelemahan. Untuk mengatasi masalah tersebut Pemerintah Kabupaten Pelalawan membuat suatu kebijakan untuk memotivasi Pegawai Negeri Sipil dalam Pelaksanaan tugas. Kebijakan tersebut berupa Peraturan Bupati Nomor 45 Tahun 2012 tentang Perubahan Pedoman Penilaian Pegawai Negeri Sipil Berprestasi di Lingkungan Pemerintah Kabupaten Pelalawan atas perubahan dari Peraturan Bupati Nomor 41 tahun 2011.

Prestasi Pegawai Negeri Sipil merupakan salah satu indikator dalam penilaian keberhasilan suatu tujuan daerah, karena Pegawai Negeri Sipil merupakan aparatur negara yang bertanggungjawab dalam menjalankan tugas negara dalam kawasan regional. Untuk itu perlu adanya suatu penilaian terhadap kinerja Pegawai Negeri Sipil khususnya pada daerah Pemerintahan Kabupaten Pelalawan, yang bertujuan untuk peningkatan prestasi kerja dan membangun semangat kompetitif antara Pegawai Negeri Sipil berprestasi di Lingkungan Pemerintah Kabupaten Pelalawan.

Kebijakan Peraturan Bupati Nomor 45 Tahun 2012 dirumuskan agar memotivasi Pegawai Negeri Sipil dalam berprestasi yang tentunya kesempatan serta ketentuan ini berlaku untuk semua Pegawai Negeri Sipil di wilayah Pemerintahan Kabupaten Pelalawan. Keberhasilan itu ditandai dengan prestasiprestasi yang diberikan oleh Pegawai Negeri Sipil terhadap kinerja yang mereka laksanakan.

\section{KAJIAN PUSTAKA}

Kata kebijakan merupakan terjemahan dari policy yang biasanya dikaitkan dengan keputusan pemerintah karena pemerintahlah yang memiliki wewenang atau kekuasaan untuk mengarahkan masyarakat dan bertanggung jawab untuk melayani kepentingan umum (Abidin, 2012)

Batasan mengenai kebijakan publik juga disampaikan oleh Carl Frederich dalam Wahab (2001) suatu tindakan yang mengarah pada tujuan yang diusulkan oleh seseorang, kelompok atau pemerintah dalam lingkungan tertentu sehubungan dengan adanya hambatan-hambatan tertentu seraya mencari peluang-peluang untuk mencapai tujuan atau mewujudkan sasaran yang diinginkan.

Menurut Wilson dalam Wahab (2001) kebijakan publik adalah sebagai berikut: "tindakan-tindakan, tujuan-tujuan, dan pernyataan-pernyataan pemerintah mengenai masalah-masalah tertentu, langkah-langkah yang telah/sedang diambil (atau gagal diambil) untuk diimplementasikan, dan penjelasan-penjelasan yang diberikan oleh mereka mengenai apa yang telah terjadi (atau tidak terjadi)".

Pelaksanaan (Implementasi) menurut Daniel Mazmanian dan Paul Sabatier dalam Agustino (2006), yaitu: "Pelaksanaan (implementasi) kebijakan 
adalah pelaksanaan keputusan kebijaksanaan dasar, biasanya dalam bentuk Undang-undang, namun dapat pula berbentuk perintah-perintah atau keputusan eksekutif yang penting atau keputusan badan peradilan. Lazimnya, keputusan tersebut mengidentifikasikan masalah yang ingin dibatasi, menyebutkan secara tegas tujuan dan sasaran yang ingin dicapai, dan berbagai cara untuk

George Edwards III dalam Nugroho, (2012) menjelaskan tentang implementasi sebagai: "......... the key issue of policy is the lack of attention toward public policy's implementation, it is stated strongly that without an effective implementation, the decision of policymakers will not be successfully carried out. Hence, Edward suggested to put attention toward four key issues: communication, resource, disposition of attitudes, and bureaucratic structures." (...isu utama kebijakan adalah kurangnya perhatian terhadap implementasi kebijakan publik. Ditegaskan dengan kuat bahwa tanpa implementasi efektif, keputusan pembuat kebijakan tidak akan berhasil diwujudkan. Oleh karena itu Edwards menekankan untuk memperhatikan empat isu utama, yaitu komunikasi, sumber daya, sikap, dan struktur birokrasi).

Van Meter dan Van Horn dalam Syafri dan Setyoko (2008) mendefinisikan implementasi kebijakan sebagai "those actions by public and private, individuals (or groups) that are directed at the achievement of objectives set forth in prior policy decisions". Definisi tersebut bermakna bahwa implementasi kebijakan adalah tindakan-tindakan yang dilakukan oleh pemerintah dan swasta , individuindividu (dan kelompok) yang diarahkan pada pencapaian tujuan/sasaran yang telah ditetapkan.

Menurut Hassel Nogi (2003) pembuatan kebijakan yang baik dapat dilakukan dengan cara:

1. Kebijakan harus relevan terhadap kebutuhan masyarakat,

2. Kebijakan harus memiliki alternatif pemecahan masalah,

3. Kebijakan harus mempunyai tujuan yang jelas, dan

4. Kebijakan harus memiliki evaluasi pelaksanaan.

Sesuai dengan perumusan masalah diatas, tujuan adalah untuk mengetahui dan menganalisa faktor yang mempengaruhi implementasi Peraturan Bupati Nomor 45 Tahun 2012 tentang Perubahan Pedoman Penilaian Pegawai Negeri Sipil Berprestasi di Lingkungan Pemerintah Kabupaten Pelalawan.

\section{METODE}

Penelitian ini menggunakan metode deskriptif kualitatif. Sumber data berasal dari data primer, diperoleh langsung dari informan yang berhubungan dengan penilaian Pegawai Negeri Sipil berprestasi di Lingkungan Pemerintah Kabupaten Pelalawan. Informan penelitian Kepala Bidang Pembinaan Pegawai Badan Kepegawaian Daerah Kabupaten Pelalawan. Pejabat Pelaksana Teknis Kegiatan penilaian PNS berprestasi. Pegawai Negeri Sipil yang mengikuti penilaian dan mendapatkan sebagai Pegawai Negeri Sipil berprestasi. Pegawai 
Negeri Sipil yang mengikuti penilaian dan belum berhasil sebagai PNS berprestasi. Pegawai Negeri Sipil yang tidak mengikuti penilaian PNS berprestasi. Dan data sekunder bersumber dari buku-buku referensi yang berhubungan dengan penelitian serta sumber-sumber lainnya seperti dokumentasi, arsip, serta data-data instansi yang terkait. Teknik pengumpulan data menggunakan observasi, wawancara dan dokumentasi. Analisis data menggunakan teknik trianggulasi yaitu trianggulasi dalam hal teori, trianggulasi dalam hal metode, trianggulasi dalam hal observer.

\section{HASIL DAN PEMBAHASAN}

Kebijakan Peraturan Bupati Nomor 45 tahun 2012 di rumuskan agar memotivasi Pegawai Negeri Sipil dalam berprestasi yang tentunya kesempatan serta ketentuan ini berlaku untuk semua Pegawai Negeri Sipil di wilayah Kabupaten Pelalawan. Namun ini belum terealisasikan dengan baik, terbukti dari data yang penulis peroleh dari tahun 2011 sampai Tahun 2013. Berikut adalah jumlah Pegawai Negeri Sipil di Kabupaten Pelalawan Tahun 2011 sampai dengan Tahun 2013.

Tabel 1. Jumlah PNS Kabupaten Pelalawan Tahun 2011-2013

\begin{tabular}{ccccc}
\hline \multirow{2}{*}{ No } & Uraian & $\begin{array}{c}\text { Jumlah PNS } \\
\text { Tahun 2011 }\end{array}$ & $\begin{array}{c}\text { Jumlah PNS } \\
\text { Tahun 2012 }\end{array}$ & $\begin{array}{c}\text { Jumlah PNS } \\
\text { Tahun 2013 }\end{array}$ \\
\hline 1 & Esselon, & & & \\
& Golongan: & 35 & 38 & 38 \\
& II & 156 & 181 & 182 \\
& III & 548 & 603 & 647 \\
\hline & IV & & & \\
& Non-Esselon, & 536 & 556 & 535 \\
& Golongan: & 1.847 & 1.951 & 2.035 \\
& IV & 2.025 & 1.752 & 628 \\
\hline & III & 68 & 49 & 5.129 \\
\hline
\end{tabular}

Sumber: Bidang Informasi dan Dokumentasi Kepegawaian BKD Kabupaten Pelalawan (2014)

Dari Tabel 1 diatas diketahui jumlah Pegawai Negeri Sipil di Kabupaten Pelalawan tahun 2011-2013 didominasi golongan II dan golongan III, selanjutnya disusul golongan IV baik yang esselon maupun non esselon. Untuk golongan I jumlahnya tidak terlalu banyak. Dari jumlah Pegawai Negeri Sipil tersebut diatas terlihat peserta yang mempunyai kesempatan untuk mengikuti program Pegawai Negeri Sipil berprestasi sangat besar untuk semua kategori.

Dalam pelaksanaan penilaian Pegawai Negeri Sipil berprestasi belum mendapat apresiasi yang tinggi dari Pegawai Negeri Sipil sebagai sasaran kebijakan. Sesuai data yang diperoleh penulis sebagai berikut: 
Tabel 2. PNS Kabupaten Pelalawan yang mengikuti Penilaian PNS Berprestasi Tahun 2011

\begin{tabular}{|c|c|c|c|c|}
\hline \multirow[b]{2}{*}{ No } & \multirow[b]{2}{*}{ Uraian } & \multicolumn{3}{|c|}{ Jumlah PNS Tahun 2011} \\
\hline & & Esselon III & Esselon IV & $\begin{array}{c}\text { Non-Esselon/ } \\
\text { Staf }\end{array}$ \\
\hline \multirow[t]{2}{*}{1} & PNS mengikuti seleksi ADM & 3 & 3 & 2 \\
\hline & Nama SKPD/ Instansi & $\begin{array}{l}\text { Inspektorat, } \\
\text { DPKKD, BLH }\end{array}$ & $\begin{array}{l}\text { DPKKD, Diskes, } \\
\text { BKP }\end{array}$ & $\begin{array}{l}\text { Diskes, Dinas } \\
\text { Perikanan \& } \\
\text { Kelautan }\end{array}$ \\
\hline 2 & $\begin{array}{l}\text { PNS Tidak Memenuhi Syarat } \\
\text { Nama SKPD/ Instansi }\end{array}$ & - & - & - \\
\hline \multirow[t]{2}{*}{3} & PNS Memenuhi Syarat & 3 & 3 & 2 \\
\hline & Nama SKPD/ Instansi & $\begin{array}{l}\text { Inspektorat, } \\
\text { DPKKD, BLH }\end{array}$ & $\begin{array}{l}\text { DPKKD, Diskes, } \\
\text { BKP }\end{array}$ & $\begin{array}{l}\text { Diskes, Dinas } \\
\text { Perikanan \& } \\
\text { Kelautan }\end{array}$ \\
\hline
\end{tabular}

$4 \quad$ PNS berprestasi $\quad 1 \quad 11$

Sumber: Bidang Pembinaan Pegawai Daerah BKD Kabupaten Pelalawan (2014)

Dari Tabel 2 mengenai data Pegawai Negeri Sipil yang mengikuti seleksi administrasi Penilaian Pegawai Negeri Sipil Berprestasi pada kategori Esselon III hanya terdapat 3 dari tiga SKPD, kategori Esselon IV juga 3 dari tiga SKPD dan untuk Non Esselon/ staf berjumlah 2 dari dua SKPD. Angka tersebut terlalu kecil jika di bandingkan dengan jumlah Pegawai Negeri Sipil dari masing-masing kategori yaitu Esselon dan Non Esselon pada tabel 1.1 diatas yang berjumlah besar. Dibawah ini merupakan tabel jumlah Pegawai Negeri Sipil Kabupaten Pelalawan yang mengikuti penilaian Pegawai Negeri Sipil berprestasi Tahun 2012.

Tabel 3. PNS Kabupaten Pelalawan yang mengikuti Penilaian PNS Berprestasi Tahun 2012

\begin{tabular}{|c|c|c|c|c|}
\hline \multirow[b]{2}{*}{ No } & \multirow[b]{2}{*}{ Uraian } & \multicolumn{3}{|c|}{ Jumlah PNS Tahun 2012} \\
\hline & & Esselon III & Esselon IV & $\begin{array}{c}\text { Non-Esselon/ } \\
\text { Staf }\end{array}$ \\
\hline \multirow[t]{2}{*}{1} & PNS mengikuti seleksi ADM & 6 & 9 & 3 \\
\hline & Nama SKPD/ Instansi & $\begin{array}{l}\text { Bappeda, DPKKD, } \\
\text { BKP, Disperindag } \\
\text { BKD, Disdukcapil }\end{array}$ & $\begin{array}{l}\text { Bappeda, } \\
\text { Disperindag, } \\
\text { DPKKD, } \\
\text { Disdukcapil, BKP, } \\
\text { Dinas Kehutanan } \\
\text { BKD, Kantor Arsip, } \\
\text { KPPT }\end{array}$ & $\begin{array}{l}\text { Bappeda, DPKKD, } \\
\text { BKD }\end{array}$ \\
\hline \multirow[t]{2}{*}{2} & PNS Tidak Memenuhi Syarat & 1 & 2 & 1 \\
\hline & Nama SKPD/ Instansi & Disdukcapil & $\begin{array}{l}\text { Disdukcapil, } \\
\text { DPKKD }\end{array}$ & DPKKD \\
\hline 3 & PNS Memenuhi Syarat & 5 & 7 & 2 \\
\hline & Nama SKPD/ Instansi & $\begin{array}{l}\text { Bappeda, BKP } \\
\text { Disperindag, } \\
\text { DPKKD, BKD }\end{array}$ & $\begin{array}{l}\text { Bappeda, } \\
\text { Disperindag, } \\
\text { KPPT, Dinas }\end{array}$ & Bappeda, BKD \\
\hline
\end{tabular}




\begin{tabular}{|c|c|c|c|c|}
\hline \multirow{3}{*}{ No } & \multirow{3}{*}{ Uraian } & \multicolumn{3}{|c|}{ Jumlah PNS Tahun 2012} \\
\hline & & Esselon III & Esselon IV & $\begin{array}{c}\text { Non-Esselon/ } \\
\text { Staf }\end{array}$ \\
\hline & & \multicolumn{3}{|c|}{$\begin{array}{l}\text { Kehutanan, Ktr } \\
\text { Arsip BKP, BKD }\end{array}$} \\
\hline \multirow[t]{2}{*}{4} & PNS berprestasi & 1 & 1 & 1 \\
\hline & SKPD/ Instansi & Disperindag & Disperindag & BKD \\
\hline
\end{tabular}

Pada Tabel 3 terjadi peningkatan jumlah peserta Pegawai Negeri Sipil yang mengikuti Penilaian Pegawai Negeri Sipil Berprestasi di Lingkungan Pemerintah Kabupaten Pelalawan. Tahun 2011 jumlah Pegawai Negeri Sipil yang mengikuti seleksi administrasi berjumlah 8 untuk semua kategori menjadi 18 pada Tahun 2012, juga terdapat peserta yang tidak memenuhi syarat administrasi berjumlah 4 dari dua SKPD untuk semua kategori. Ini disebabkan karena Pegawai Negeri Sipil yang mengikuti penilaian Pegawai Negeri Sipil berprestasi tersebut tidak melengkapi data sesuai persyaratan yang terdapat dalam Peraturan Bupati Nomor 45 Tahun 2012 tentang Perubahan Pedoman Penilaian Pegawai Negeri Sipil Berprestasi di Lingkungan Pemerintah Kabupaten Pelalawan. Berikut tabel jumlah Pegawai Negeri Sipil yang mengikuti penilaian Pegawai Negeri Sipil berprestasi pada Tahun 2013.

Tabel 4. PNS Kabupaten Pelalawan yang mengikuti Penilaian PNS Berprestasi Tahun 2013

\begin{tabular}{|c|c|c|c|c|}
\hline \multirow[b]{2}{*}{ No } & \multirow[b]{2}{*}{ Uraian } & \multicolumn{3}{|c|}{ Jumlah PNS Tahun 2013} \\
\hline & & Esselon III & Esselon IV & $\begin{array}{c}\text { Non Esselon/ } \\
\text { Staf }\end{array}$ \\
\hline \multirow[t]{2}{*}{1} & $\begin{array}{l}\text { PNS mengikuti seleksi } \\
\text { ADM }\end{array}$ & 6 & 8 & 3 \\
\hline & Nama SKPD/ Instansi & $\begin{array}{l}\text { Dinas Peternakan, } \\
\text { Diskes, Bappeda, } \\
\text { Disbud parpora, } \\
\text { Diskesos, BKD }\end{array}$ & $\begin{array}{l}\text { Dinas Peternakan, } \\
\text { BLH, Diskes, } \\
\text { BPPPA \& KB, } \\
\text { Setda, BKD, } \\
\text { Diskesos }\end{array}$ & $\begin{array}{l}\text { Dinas Peternakan, } \\
\text { Diskes, BKD }\end{array}$ \\
\hline \multirow[t]{2}{*}{2} & $\begin{array}{l}\text { PNS Tidak Memenuhi } \\
\text { Syarat }\end{array}$ & - & 3 & - \\
\hline & Nama SKPD/ Instansi & & $\begin{array}{l}\text { Diskes, BPPPA \& } \\
\text { KB }\end{array}$ & \\
\hline \multirow[t]{2}{*}{3} & PNS Memenuhi Syarat & 6 & 5 & 3 \\
\hline & Nama SKPD/ Instansi & $\begin{array}{l}\text { Dinas Peternakan, } \\
\text { Diskes,Bappeda, } \\
\text { Disbud parpora, } \\
\text { Diskesos, BKD }\end{array}$ & $\begin{array}{l}\text { Dinas Peternakan, } \\
\text { BLH, Diskesos, } \\
\text { Setda, BKD }\end{array}$ & $\begin{array}{l}\text { Dinas Peternakan, } \\
\text { Diskes, BKD }\end{array}$ \\
\hline \multirow[t]{2}{*}{4} & PNS berprestasi & 2 & 2 & 2 \\
\hline & SKPD/ Instansi & $\begin{array}{l}\text { Dinas Peternakan, } \\
\text { Bappeda }\end{array}$ & Setda, BLH & Diskes, BKD \\
\hline
\end{tabular}


Pada Tabel 4 dapat diketahui terjadi penurunan jumlah Pegawai Negeri Sipil yang mengikuti Penilaian Pegawai Negeri Sipil Berprestasi, walaupun hanya satu angka yaitu dari 18 Pegawai Negeri Sipil yang mengikuti seleksi administrasi pada tahun 2012 menjadi 17 Pegawai Negeri Sipil yang mengikuti seleksi administrasi pada tahun 2013 untuk semua kategori. Pegawai Negeri Sipil yang Tidak Memenuhi Syarat (TMS) administrasi penilaian Pegawai Negeri Sipil berprestasi menjadi berkurang yaitu Tahun 2012 Pegawai Negeri Sipil yang Tidak Memenuhi Syarat (TMS) berjumlah 4 manjadi 3 pada Tahun 2013 dan terjadi peningkatan jumlah Pegawai Negeri Sipil yang menjadi Pegawai Negeri Sipil berprestasi.

Implementasi kebijakan publik pada prinsipnya adalah cara agar sebuah kebijakan dapat mencapai tujuannya. Namun dari data yang penulis peroleh dan uraikan diatas, didapati masih sedikit jumlah Pegawai Negeri Sipil yang mengikuti dalam penilaian Pegawai Negeri Sipil berprestasi di Lingkungan Pemerintah Kabupaten Pelalawan.

Implementasi Peraturan Bupati Nomor 45 Tahun 2012 tentang Perubahan Pedoman Penilaian Pegawai Negeri Sipil Berprestasi di Lingkungan Pemerintah Kabupaten Pelalawan berdasarkan mekanisme pelaksanaan yaitu:

1. Tahapan Persiapan Administrasi.

Kelengkapan administrasi diberikan setelah diterimanya Surat Edaran yang dikeluarkan Bupati untuk melakukan seleksi Pegawai Negeri Sipil berprestasi.

Berdasarkan hasil wawancara dalam penelitian disimpulkan bahwa dalam menyampaikan edaran pelaksanan seleksi Pegawai Negeri Sipil berprestasi, panitia menyebarkannya masih secara manual. Sehingga beberapa SKPD terlambat mendapatkan informasi untuk mengikuti penilaian Pegawai Negeri Sipil berprestasi. Bagi Pegawai Negeri Sipil yang telah mengikuti persyaratan administrasi, harus Memenuhi Syarat (MS) untuk mengikuti seleksi selanjutnya.

\section{Tahap Persiapan Ujian}

Dalam tahapan ini merupakan penentuan jadwal ujian dan pelaksanaan ujian penilaian Pegawai Negeri Sipil berprestasi di Lingkungan Pemerintah Kabupaten Pelalawan terdiri dari mengoperasikan komputer, bahasa inggris dan wawancara. Pelaksanaan ujian penilaian Pegawai Negeri Sipil berprestasi berjalan sebagaimana mestinya sesuai dengan prosedur yang telah ditetapkan.

3. Tahapan akhir (hasil)

Tahapan ini hasil penilaian Pegawai Negeri Sipil berprestasi akan di umumkan dan selanjutnya pemberangkatan. Yang diumumkan dari hasil penilaian Pegawai Negeri Sipil berprestasi hanya nama Pegawai Negeri Sipil yang berhasil menjadi Pegawai Negeri Sipil berprestasi. Hasil dari setiap penilaian berguna sebagai evaluasi diri bagi Pegawai Negeri Sipil untuk penilaian kedepan. 
Dalam melakukan penelitian dengan kajian ilmiah penulis menggunakan teori yang dikemukakan oleh Edward III yaitu dipengaruhi oleh Komunikasi, Sumber daya, Disposisi/ sikap dan struktur birokrasi.

\section{Aspek Komunikasi}

Komunikasi adalah suatu kegiatan manusia untuk menyampaikan apa yang menjadi pemikiran dan perasaannya, harapan atau pengalamannya kepada orang lain. Penyampaian informasi kebijakan dan pelaksanaan penilaian Pegawai Negeri Sipil di Lingkungan Pemerintah Kabupaten Pelalawan masih melalui surat-menyurat untuk disampaikan kepada sasaran kebijakan.

Sosialisasi penilaian Pegawai Negeri Sipil berprestasi belum menggunakan teknologi secara maksimal sehingga belum efektif dan efisien dalam penyampaiannya. Penyampaian informasi masih menggunakan secara surat menyurat dan penyampaian lisan sehingga belum mencapai sasaran kebijakan secara keseluruhan yaitu Pegawai Negeri Sipil di Lingkungan Pemerintah Daerah Kabupaten Pelalawan.

\section{Aspek Sumberdaya}

Efektivitas pelaksanaan kebijakan sangat tergantung kepada sumberdaya baik Sumber Daya Manusia maupun Sumber Daya Anggaran. Sumber Daya Manusia sebagai pelaksana kebijakan ditunjuk sesuai dengan prosedur dan ditetapkan dalam Surat Keputusan Bupati. Panitia memahami tugas dan fungsinya dalam pelaksanaan kegiatan.

Anggaran pelaksanaan masih mangalami kekurangan biaya operasional sehingga kegiatan belum berjalan dengan baik dan Sumber Daya Manusia dalam hal ini panitia pelaksana tidak dapat di manfaatkan secara maksimal. Jumlah Pegawai Negeri Sipil yang berhasil penjadi Pegawai Negeri Sipil berprestasi di Lingkungan Pemerintah Kabupaten Pelalawan masih sedikit.

\section{Aspek Disposisi.}

Disposisi diartikan sebagai kecenderungan, keinginan atau kesepakatan para pelaksana untuk melaksanakan kebijakan. Jika implementasi kebijakan ingin berhasil secara efektif dan efisien, para pelaksana tidak hanya mengetahui apa yang harus dilakukan dan mempunyai kemampuan untuk melakukan kebijakan itu. Panitia pelaksana telah memberikan pelayanan dengan baik kepada peserta disaat pelaksanaan kegiatan penilaian Pegawai Negeri Sipil berprestasi di Lingkungan Pemerintah Kabupaten Pelalawan. Dan peserta penilaian Pegawai Negeri Sipil berprestasi merasa nyaman selama mengikuti ujian.

\section{Aspek Struktur Birokrasi}

Bagian yang terpenting dalam organisasi kebijakan adalah adanya Standar Operasional Prosedur (SOP). Kegunaan SOP merupakan suatu pedoman tertulis yang dipergunakan untuk menggerakkan pelaksana dalam pembagian tugas agar organisasi yang dijalankan efektif sehingga tujuan yang ditetapkan dapat terealisasikan. 
Dalam wawancara peneliti ditemukan bahwa dalam kegiatan penilaian PNS berprestasi belum mempunyai Standar Operasional Prosedur. Pedoman pelaksanaan kegiatan menggunakan petunjuk yang terdapat dalam Peraturan Bupati Nomor 45 Tahun 2012 tentang Perubahan Pedoman Penilaian Pegawai Negeri Sipil Berprestasi di Lingkungan Pemerintah Kabupaten Pelalawan.

\section{KESIMPULAN}

Implementasi Peraturan Bupati Nomor 45 Tahun 2012 tentang Perubahan Pedoman Penilaian PNS Berprestasi di Lingkungan Pemerintah Kabupaten Pelalawan berdasarkan mekanisme pelaksanaan dan implementasi kebijakan berdasarkan teori Edward. 1) Tahap Persiapan Administrasi. Dalam Tahap Persiapan Ujian kegiatan penilaian Pegawai Negeri Sipil berprestasi di Lingkungan Pemerintah Kabupaten Pelalawan, panitia pelaksana telah melaksanakan tugas sesuai tugas dan fungsi sehingga kegiatan berjalan baik. 2) Komunikasi. Penyampaian informasi kepada sasaran kebijakan belum berjalan secara efekti dan efisien tentang pelaksanaan kegiatan penilaian Pegawai Negeri Sipil berprestasi di Lingkungan Pemerintah Kabupaten Pelalawan. Fasilitas teknologi belum digunakan secara maksimal untuk menunjang sosialisasi kepada Pegawai Negeri Sipil sebagai sasaran kebijakan. 3) Struktur Organisasi. Kegiatan penilaian Pegawai Negeri Sipil berprestasi di Lingkungan Pemerintah Kabupaten Pelalawan belum membentuk Standar Operasional Prosedur yang merupakan suatu pedoman tertulis untuk pelaksanaan dan pembagian tugas secara efektif sehingga tujuan yang ditetapkan dapat terealisasi dengan baik.

Faktor-faktor yang mempengaruhi Implementasi Peraturan Bupati nomor 45 Tahun 2012 tentang Perubahan Pedoman Penilaian Pegawai Negeri Sipil Berprestasi di Lingkungan Pemerintah Kabupaten Pelalawan adalah faktor konsistensi, motivasi, koordinasi.

\section{DAFTAR PUSTAKA}

Abidin, S. Z. 2012. Kebijakan Publik: Edisi Kedua. Jakarta: Salemba Humanika.

Agustino, L. 2006. Dasar-dasar Kebijakan Publik: Cetakan Pertama. Bandung: CV Alfabeta.

Hassel, N. 2003. Evaluasi Kebijakan Publik. Yogyakarta: Balairung \& Co.

Nugroho, D. R. 2012. Public Policy: Dinamika Kebijakan, Analisis Kebijakan, Manajemen Kebijakan: Edisi Keempat. Jakarta: PT Elex Media Komputindo.

Syafri, W. H., dan Setyoko, I. P. 2008. Implementasi Kebijakan Publik dan Etika Profesi Pamong Praja. Jatinangor: Alqaprint.

Wahab, S. A. 2001. Analisis Kebijakan dari Formulasi ke Implementasi Kebijakan Negara. Jakarta: Bumi aksara. 